\title{
Well-being by Formula? Exploring the Role of Somaesthetics in Making Self-tracking More Sustainable
}

\author{
Xue $\mathrm{Wu}^{1}$, Han-Teng $\mathrm{Liao}^{1}$, Man $\mathrm{Zhao}^{1 *}$ \\ ${ }^{1}$ New Media Research Centre, Sun Yat-sen University Nanfang College, Guangzhou, Guangdong, 510970, China
}

\begin{abstract}
Self-tracking, a phenomenon which dataify individuals' daily activities and experiences, presents both opportunities and challenges to understand which factors and in what ways may influence individuals' health status or well-being. Technology can enhance the era of personal happiness and increase social wellbeing. We hope to provide a design principle and operational design method to promote the well-being consideration of self-tracking products and technologies. In order to propose such principles and methods, it is necessary to first analyze the key factors of happiness in using self-tracking products. This article proposes "The Self-tracking Sustainability Formula", which includes three elements as information, well-being drives, and material. Such a formula could possibly conceptually explain the components of a self-tracking product with sustainable potential. On this basis, this paper further explores how self-tracking products can positively influence issues such as environmental protection, personnel management, and friendly social relations from the dimensions of "information" and "well-being drives" to form more sustainable. Production and consumption ecology. This paper argues that, in order to enhance such a process of sustainable well-being, we as user researchers and product designers must design better ways of visualizing and interacting with "datafied well-being". From the citations of dashboards, we draw upon both the principles of Somaesthetics to propose an "avatar" as the central interface component. An avatar, or a humanized animal image, is proposed to provide a more intuitive understanding of one's physical, emotional, and social well-being, looking forward to helping self-tracking products become more sustainable by considering sustainable design principles and forms in the design process and motivating users to be more willing to accept sustainability Self-tracking products.
\end{abstract}

\section{INTRODUCTION}

The potential impact of technology on our lives is unprecedented. Digital technology that lacks people's care may increase people's stress and suffering, but we hope that technology can improve the living standards of individuals or groups. Economists measure the national happiness index mainly at the national level. Psychologists measure people's happiness at the individual level[1]. However, the technology industry is paying more and more attention to social welfare such as self-awareness, human happiness, and social significance. Research, such as the Internet of People (IoP)[2], Compute within Limits[3], Tech for Good[4], Design for Good[5] has grown in a fast speed recent years. So, from the perspective of human-computer interaction, explore how to consider numbers from a design perspective. The happiness factor in the product is meaningful and necessary. In our previous study[6], we drew upon the principles of Somaesthetics to propose "an avatar template" as a central interface component of self-tracking products and technologies related, which is proposed to provide a more intuitive understanding of one's physical, emotional, and social well-being.
In this paper, we would like to open a discussion on can self-tracking APP provide information used to say something about well-being? How could it be used to affect well-being, e.g. empathy, social relationship? And how should it be designed? These questions concerning self-tracking data and well-being will be discussed in this paper. We argued in this paper that self-tracking can be an important point for both product innovations and policy interventions, with the aim to align on one side, the individual desire for self-improvement through selfknowledge, and on the other, the behavior changes that lead to healthier and more caring individuals, and also lead to the more sustainable natural environment.

\section{BACKGROUND AND RELATED WORK}

In this section, we first reviewed the current research on the relationship between "self-tracking", "well-being" and "SPC (Sustainable Production, Consumption)" to confirm that big data can reflect people's well-being degree, and it will have an impact on the well-being of individuals and society. This is the research foundation as we choose selftracking products as our research objects. Secondly, we found that in Chinese academic circles, In Chinese academic circles, research on SPC and Well-being rarely

*Corresponding author's e-mail: manzhao_zm@outlook.com 
involves digital technology, which provides a valuable space for research as we put forward the design principle and method for making self-tracking more sustainable.

There is no direct relationship between overconsumption and well-being. Similarly, a shortage of consumption or insufficient consumption cannot make people feel happy, not only causing physical and mental harm to the parties but even threatening the environment. This issue has reached a consensus in the field of consumer ecology. In the CNKI, only 29 journal articles currently discuss " sustainable consumption" and "well-being” . Using formula with alias and synonyms: $\mathrm{SU}=($ 'sustainable consumption' + 'green consumption' + 'sustainable production' + ' sustainable consumption and production') *('happiness' + 'well-being') in CNKI ) 。 Among the 29 search results, the most cited journal articles on the basis of collecting and analyzing the current situation of China's consumer ecology. Digital technologies including drones, sensors, GPS, and big data crunching algorithms have not been included in the study, to the analysis of how digital technologies' production and consumption affect people's well-being, or what operational knowledge or principles digital technology should follow to move toward sustainability.

In many instances, digitization and the product equation constitute an invaluable framework for thinking and acting strategically about the sustainability of products and business[9]. For example, "station-free" bike-sharing platform operated via the online mobile application, like Ofo and Mobike, have hit the consumer market in the past few years. The market share of selfowned bicycles has shrunk, and some companies' sales have fallen by more than $50 \%[10]$, more than 50,000 vehicles with damaged and abandoned shared vehicles[11]. This is a very typical case of the overconsumption of digital products.

In fact, the data products in people's daily life are almost all included in the function of material consumption. For example, the products of self-tracking products and technologies, Meiyou APP and Dayima APP, also provide shopping malls in the APP, selling products of third-party platforms, and more reports. It is proposed that this APP is developing a customized merchandise business. In the following, we conducted a case study of Meiyou APP and Dayima APP to determine the key factors for the happiness of using such products.

\section{THE SELF-TRACKING SUSTAINABILITY FORMULA}

Digitization is transforming entire industries, holding out the possibility of significantly improving well-being performance includes physical health, mental health, social relationship, environmental, and so on. An emerging area of opportunity is the digitization of daily life self-tracking products and production. In this article, in order to understand the key factors of self-tracking products and technologies that bring well-being to consumers, we need to first analyze the components of self-tracking products. In[9], conceptualized elements of any product have been put forward as the materials + information+energy=products formula, which is called "The Environmental Sustainability Formula". Every transformation of materials is the application of energy guided by information. By conceptualizing a combination of matter, energy, and information, digitization of physical products and production has become an emerging idea in sustainability.

In the analysis of the key factors of happiness in selftracking products, we borrowed "The Environmental Sustainability Formula" by Gregory Unruh and David Kiron to further develop "The Self-tracking Sustainability Formula", which includes three elements as "Information", "Well-being drives" and "Material", which conceptually explain the components of a selftracking product with sustainability potential.

We will mainly use the Dayima APP and Meiyou APP as an example to analyze the meaning of the various elements in the formula, and the key factors in the sustainable production and consumption, and the key factors for the user's happiness.

\subsection{Material}

In the original formula, Gregory, Unruh and David Kiron explained that digitalization can be environmentally sustainable since the same product was provided to customers but much of its physical attributes - raw material and energy - had become digitized. In "the Selftracking Sustainability Formula", the element "Material" represents the consumer behavior of self-tracking hardware products, such as the purchase of Xiaomi bracelet, Fitbit, etc, and the consumer behavior within the self-tracking application, such as the "Mall" feature provided in the Meiyou APP, Dayima APP. The material product itself (Millet bracelet, Fitbit) and the digital product function ("Mall" function) enable consumers to produce actual physical commodity consumption, so whether it is traditional to buy products in stores, or more extensive e-commerce, self-tracking products, and technologies. To develop sustainable production and consumption, it is necessary to consider the rationality and consumption patterns of the consumption of such substances.

Take the "Mall" function provided in the Meiyou APP and Dayima APP as an example. After selecting an item in the APP page, it will automatically jump to the Taobao APP to complete the purchase. The material goods consumption function provided to users in the APP is the curation of the content of the third-party platform. The importance of Curation is how some people's choices influence people's attention and lay the foundation for a new way to accumulate and manage knowledge. [14]. For Meiyou and Dayima, this function is a key business for sustainable production and consumption. The sustainability of digital products over traditional products lies in the number of raw materials, less energy consumption, and waste. For example, compared to the curation of third-party products, Meiyou and Dayima can promote the customization of goods through the 
segmentation of consumers, thereby increasing the matching between product functions and consumer demand, and reducing the waste of goods; How Meiyou and Dayima should reduce e-commerce's logistics energy and material consumption in order to make a positive contribution to the SCP rather than increase the burden.

\subsection{Information}

In "the Self-tracking Sustainability Formula", the element "Information" represents self-tracking products and technologies that record data generated by people's daily lives. At present, in the self-tracking product, the phenomenon of excessive data is very common, and unnecessary data collection and calculation cause waste of computing resources and communication resources. The concept of "computing within limits" or "LIMITS" for short is not concerned with the material impacts of computation itself but engages a deeper, transformative shift in computing research and practice to one that would use computing to contribute to the overall process of transitioning to a future in which the well-being of humans and other species is the primary objective[3]. Self-tracking products and technologies should establish appropriate data collection and calculation rules to complete the rational use of computing resources and communication resources, and use green digital resources such as green hosting for big data operations.

Another important implication of the "Information" element is the data display form of the Self-tracking product. The data is usually presented in the form of a dashboard interface, including the parameters of detailed data and trendlines, which record data such as steps, calories, heart rate, sleep time, deep sleep, weight, and water consumption. And the dashboard interface with excessive data display can really help users to improve their daily behavior, or is it just a comforting self-mastery - the user's illusion controls their daily life, but there is no actual behavior change? The result of this problem will affect the user's willingness to continue to use it.

\subsection{Well-being Drives}

The element "Well-being Drives" represents drivers of happiness such as positive emotions, motivation, commitment, self-awareness, righteous thoughts, empathy, compassion, environmental friendliness, sociality, and altruism. Technology has a tremendous ability to promote factors that are associated with well-being, and selftracking products and technologies need to investigate what strategies can be used to develop these factors.

Since many digital products do not take well-being into consideration during the design process, digital technology does not bring happiness to people. This phenomenon is mainly since engineers and scientists often avoid the influence of psychological factors such as wellbeing and happiness that are

difficult to quantify. The research of Positive Computing - considering happiness, sustainability, and social impact - makes it possible for designers of digital products to accurately measure "good visions" and help us conduct assessments to determine whether relevant technologies should be developed[12].

Table.1 A framework for thinking and acting strategically about the sustainability of self-tracking products, technologies and business



\section{SELF-AWARENESS \& EMPATHY BE USED IN THE DESIGN: DESIGNED FOR SUSTAINABILITY}

In analyzing the "information" and "well-being Drives" elements of Meiyou APP and Dayima APP, we refer to Rafael A. Calvo and Dorian Peters' analysis of positive computing, and they propose a framework of "key factors for well-being". The framework has narrowed the scope of research to specific factors that have been confirmed by many studies that can affect happiness, to help well-being design be more operational.

Since research has shown that the techniques of roleplaying and whole-hearted experience enable people to experience the lives and circumstances of others as much as possible, and thus increase the empathy[12]. Then selftracking product designers should also think about how to convey the information through role-playing and embodied communication to enhance the product's wellbeing drives elements. 
In order to enhance such a process of self-knowledge and empathy, we put forward a visualizing and interacting with "datafied well-being" design as "a self-presentation avatar", which is inspired by the principles of Somaesthetics. To illustrate how Somaesthetics can guide the design of self-tracking products, we correspond to aesthetic theory and product function and design. In Western aesthetics, there has always been a genre of criticism and derogation of the "body", and will this kind of thinking to be strengthened by science and technology? With the dashboard as the main interface, Self-tracking technology that uses digital, text, and static images as the means of information to separate the "body" from the "psychological", "esthetic tendency", "social tendency" and other "self" content. People's complete body is divided into different dimensions by numbers such as steps, heart rate, sleep time, calories, etc. In the face of these low-tech graphic display dimensions, people can only partially selfrecognize their own bodies, but these body numbers and What is the relationship between emotions, what is the relationship with the environment, and what is the relationship with others? These important contents of "self-awareness" and "empathy" are difficult to be presented, and it is difficult to promote people's true selfawareness and rationality[13]. Advances in technology allow Self-tracking products to record more data on everyday life. These data should not be directly displayed in front of people. Many numbers are likely to cause people to "excessively reflect" and thus generate negative emotions; Graphic sharing is not the best way to

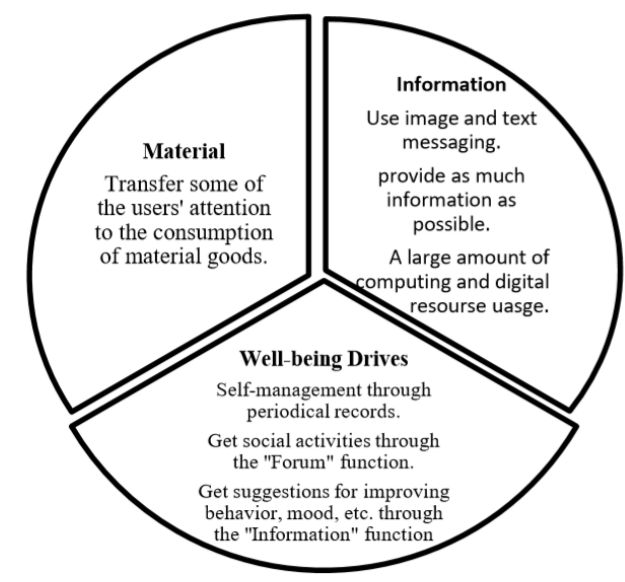

Fig.1 Positive design formula of Meiyou and Dayima APPs

\section{CONCLUSION}

This paper hopes to provide a design principle and an operational design approach to promote well-being considerations for self-tracking products and technologies designed for "Avatar" interactions based on Somaesthetics. This article presents analysis and design recommendations for sustainable self-tracking products from the perspective of user experiencers and digital product designers. As sustainable production and consumption for well-being is not a matter only for the economist, politician, social cultivate empathy. Therefore, we argued that an avatar, or a humanized animal image, is proposed to provide a more intuitive understanding of one's physical, emotional, and social well-being, as avatars may better embody the psychological status and well-being of an individual via various facial expressions and body data, fatter or slimmer presented in an interactive time slider, and to show relationships between human health and environments [19]. As stated by Somaesthetics' theory, physical training helps to achieve self-care and achieve "aesthetic selfshaping"[13]. Thus, achieving the well-being of people.

Therefore, in the case of Meiyou APP and Dayima APP, we believe that the existing product design is "positive design"[12], that is to say, although an application is not used to promote happiness, it has factors that support happiness. These factors can help people gain self-awareness, empathy, or gratitude.

By joining the Avatar template guided by Systhemetics, Meiyou APP and Dayima APP can identify factors that contribute to the generation and development of well-being and become "promoting design"[12]. That is, the purpose of the application is to increase human well-being and enhance people's potential. Avatar is the main interactive interface design to make the information appear in a form that is more suitable for people's wellbeing needs, so as to better promote the self-consciousness, empathy, positive emotion, and other well-being drives. Along with strategy adjustment and optimization design, we can get the sustainable design elements and design guidance of self-tracking products (See Fig.2).

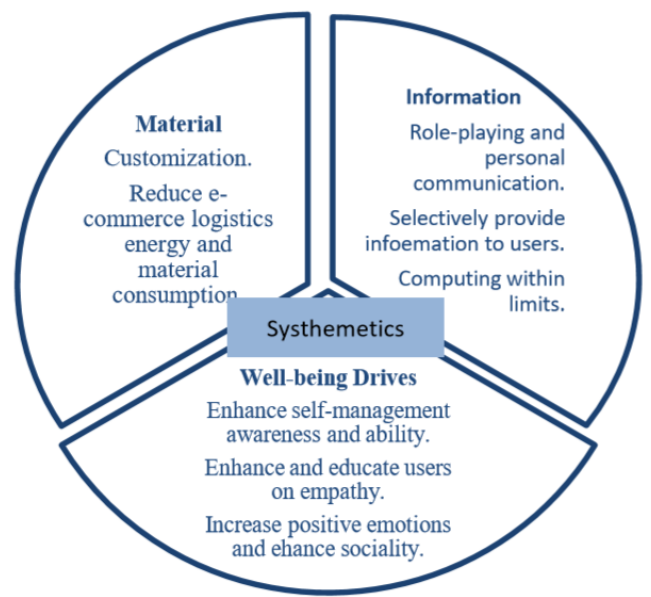

Fig.2 Sustainable design formula of Meiyou and Dayima APPs

scientist, and psychologist, but also designers for digital products, we believe that designers and developers should and must pay attention to the impact of technology on well-being. We hope that through the theoretical analysis and case study of this paper, we can provide evidence for the feasibility of considering the well-being factor in the design process of technology. We also hope to continue to explore the "Avatar" interaction design based on Somaesthetics through future research work, which could increase individual's ability to build a healthy and happy self-tracking digital environment. 


\section{ACKNOWLEDGMENTS}

The research is funded by the Application-oriented Curriculum Development Project of "Information Visualization Design" (NFU 02-40250), under the Guangdong Province Department of Education 2018 "Innovation-Strengthening Higher Education Program" Grants, and partly by a project of Innovation of Intelligent Applied Design Development (2019GXJK186), under the 2019 Special Project of philosophy and Society in Colleges and Universities of the 13th five-year Plan of Educational Science in Guangdong Province, and partly by a project of HCI for Education Development (2018WQNCX283), under the 2018 Major Projects of Guangdong Province Department of Education "Young Innovative Talents" Grants..

\section{REFERENCE}

1. Anon World Happiness Report 2019.

2. Conti, M., Passarella, A., Das, S.K. (2017) The Internet of People (IoP): A new wave in pervasive mobile computing. Pervasive Mob. Comput. 41: $1-27$.

3. Nardi, B., Tomlinson, B., Patterson, D.J., Chen, J., Pargman, D., Raghavan, B., Penzenstadler, B. (2018) Computing within limits. Commun. ACM 61: 86-93.

4. Bughin, J., Hazan, E., Allas, T., Hjartar, K., Manyika, J., Sjatil, P.E., Shigina, I. (2019) Tech for good: Smoothing disruption, improving wellbeing. (McKinsey Global Institute)

5. Valva, A. (2018) User-centred Design, Participatory Methodology and Incidental Learning of Language-culture: How to Test the Effectiveness of This Approach? The Case Study of the UniOn App. Proceedings of the 4th EAI
International Conference on Smart Objects and Technologies for Social Good Goodtechs '18 (New York, NY, USA: ACM) pp 294-297

6. Wu, X., Liao, H. (2018) Everyday Life Approach for Smart Health: A People-Centered Design Process for Co-Creating Self-Tracking Systems. 2018 IEEE SmartWorld, Ubiquitous Intelligence Computing, Advanced Trusted Computing, Scalable Computing Communications, Cloud Big Data Computing, Internet of People and Smart City Innovation (SmartWorld/SCALCOM/UIC/ATC/CBDCom/I OP/SCI) 2018 IEEE SmartWorld, Ubiquitous Intelligence Computing, Advanced Trusted Computing, Scalable Computing Communications, Cloud Big Data Computing, Internet of People and Smart City Innovation (SmartWorld/SCALCOM/UIC/ATC/CBDCom/I OP/SCI) pp 2005-10

7. Anon. A probe into $\mathrm{Xi}$ Jinping's View of Ecological Civilization - CNKI.

8. Chen Yong, Huang Qiang, (2005) On the Ethics of Sustainable consumption. Ethical Research. 63-8.

9. Unruh, G., Kiron, D. (2019) Digitizing Products for Sustainability's Sake.

10. Anon (2019) Sharing bicycles encounter "low tide" impact bicycles how to find a new driving force for development? Huaxia Longitude and Latitude Network

11. Anon (2019) More than 50,000 shared bikes will be cleaned up in Beijing in a week, and electronic fences will be added. CCTV network.

12. Calvo, R.A., Peters, D. (2014) Positive Computing: Technology for Wellbeing and Human Potential. (MIT Press)

13. Shusterman, R. (2008) Body consciousness: a philosophy of mindfulness and somaesthetics. (Cambridge; New York: Cambridge University Press) 